\title{
Occurrence and distribution of antibiotic resistance genes in the water and sediments of Qingcaosha Reservoir, Shanghai, China
}

Zhifeng Huang ${ }^{1,3}$, Wanting Zhao ${ }^{1}$, Ting $X u^{1,2^{*}}$, Binghui Zheng ${ }^{3}$ and Daqiang Yin ${ }^{1,2^{*}}$

\begin{abstract}
Background: Qingcaosha Reservoir is China's largest river impoundment and an important drinking water resource for Shanghai city. Although antibiotics contamination in the reservoir has been reported, little is known about the presence of antibiotic resistance genes (ARGs). In this study, the occurrence and distribution of 12 ARGs and the class 1 integron gene (intl-1) in water and sediments collected from the reservoir were investigated for 1 year.

Results: The 12 ARGs were detected in both water and sediment samples, and no significant temporal or spatial variations were observed. Sulfonamide resistance genes were predominant in the reservoir with a detection frequency of $100 \%$. Statistical analysis indicated a positive correlation in relative abundance between some ARGs such as sul1, sul2, and intl-1. Most ARGs were negatively correlated with total nitrogen and positively correlated with chemical oxygen demand and chlorophyll-a.

Conclusion: In general, ARGs were found to be prevalent in Qingcaosha Reservoir, among which sulfonamide resistance genes were the most dominant and tetB was the least. intl-1 may facilitate the proliferation and propagation of some ARGs, especially sul 1 and sul2. The abundance of ARGs was well correlated with aquatic environmental factors in water, providing potential clues for the control of ARG contamination.
\end{abstract}

Keywords: Antibiotic resistance genes, Drinking water reservoir, Temporal and spatial variations

\section{Background}

Antibiotics are effective against bacteria and have been widely used to treat bacterial infections in humans or animals since their discovery in the 1930s [1]. China is the largest producer and consumer of antibiotics in the world, accounting for approximately 72,700 tons of 36 common antibiotics consumed in 2013, divided equally between clinical and veterinary use [2]. Overuse of antibiotics has subjected bacteria to long-term selection pressure, leading to the development of antibiotic resistance, which indicates that the bacteria will be difficult to kill [3]. Antibiotic resistance genes (ARGs) are the core functional elements in antibiotic resistant bacteria, and

\footnotetext{
*Correspondence: xuting@tongji.edu.cn; yindq@tongji.edu.cn ${ }^{1}$ Key Laboratory of Yangtze River Water Environment, Ministry of Education, College of Environmental Science and Engineering, Tongji University, Shanghai 200092, China

Full list of author information is available at the end of the article
}

they have the ability to migrate among different microbes through horizontal gene transfer $[4,5]$. The shuttling of ARGs among various bacteria has made possible the generation of super resistant pathogens, posing a tremendous potential threat to public health [6].

Recently, ARGs have been detected in surface water [7, 8], drinking water [9], sewage treatment plants [10], wetland [11], soils [12], sediments [13], and even air [14]. The environmental abundance of ARGs is mainly caused by selection pressure from antibiotics, and by some environmental factors including microbial consortium structure and nutrients [15]. Aquatic ecosystems have been the environments of most concern in ARGs research. It has been reported that sulfonamide, tetracycline, $\beta$-lactam, and macrolide resistance genes are the most abundant ARGs in aquatic environments [16, 17]. Notably, clays in aquatic ecosystems such as in sediments are able to adsorb DNases that would otherwise hydrolyze free DNA 
(including ARGs), and thus contain a large number of microbes possessing ARGs [18]. These adherent ARGs were possibly released into water from the sediments under relatively quiescent (low-flow) condition [18]. Thus, the distribution of ARGs between water bodies and sediments merits further exploration [18, 19].

In drinking water supplies, the presence of ARGs has been believed to seriously threaten public health and thus has attracted increasing attention. Conventional water treatment techniques including sand filtration and sedimentation have difficulty completely removing ARGs, and the concentrations of ARGs can even increase after chlorine disinfection [20, 21]. These ARGs residues from drinking water treatment plants were bound to be transported to terminal consumers. Hao et al. investigated the concentrations of ARGs in the tap water of Tianjin, China, and fifteen ARGs were continuously detected in all samples [21]. Therefore, in addition to further improving treatment techniques, it is necessary to control the distribution of antibiotics and ARGs into drinking water sources. Artificial reservoirs have been constructed for water storage and supply in various countries including China. With the spread of antibiotic use, ARGs as a variety of emerging contaminant have been detected in many reservoirs in recent years [22, 23].

Qingcaosha Reservoir came into use in 2011 to replace the Huangpu River as the long-standing main water source for Shanghai, which was no longer suitable considering increasing quality requirements for clean drinking water [3]. The reservoir is located in the Yangtze River Estuary in Shanghai, eastern China, covering an area of approximately $70 \mathrm{~km}^{2}$ and with a designed effective storage capacity of 435 million cubic meters. In recent years, due to the chemical industry and sewage plant pollution from the upper reaches of the Yangtze River Estuary, the reservoir's water quality has slightly deteriorated [24]. A previous study demonstrated that various antibiotics were widely distributed in Qingcaosha Reservoir water, raising the possibility of health risks to residents [25]. However, little is known about the presence of antibiotic corresponding ARGs, and long-term continuous monitoring for this emerging risk is still lacking.

We collected both water and sediment samples from Qingcaosha Reservoir monthly for an entire year. Our main aims were to (1) characterize the occurrence, abundance, distribution, and variation of 12 ARGs and the class 1 integron gene (intI-1) in water and sediments; (2) explore the potential connections between different ARGs; and (3) determine the primary environmental factors that influence the abundances of ARGs. Our results provide annual monitoring data for the prevalence of ARGs in Qingcaosha Reservoir and yield important clues for controlling antibiotics and their corresponding ARGs in the reservoir and nearby areas.

\section{Materials and methods}

\section{Study site and sample collection}

Qingcaosha Reservoir, located in the Yangtze River Estuary in eastern China, is an important source of drinking water for a population of over 12 million in Shanghai and provides more than 7.19 million $\mathrm{m}^{3}$ of water daily. This large shallow reservoir has a surface area of $66 \mathrm{~km}^{2}$ with a depth ranging from 1.5 to $7.0 \mathrm{~m}$. It receives its fresh water supply from the Yangtze River with an average flow velocity of $0.05 \mathrm{~m} / \mathrm{s}$. Our sampling sites were located as shown in Fig. 1. Water and sediment samples

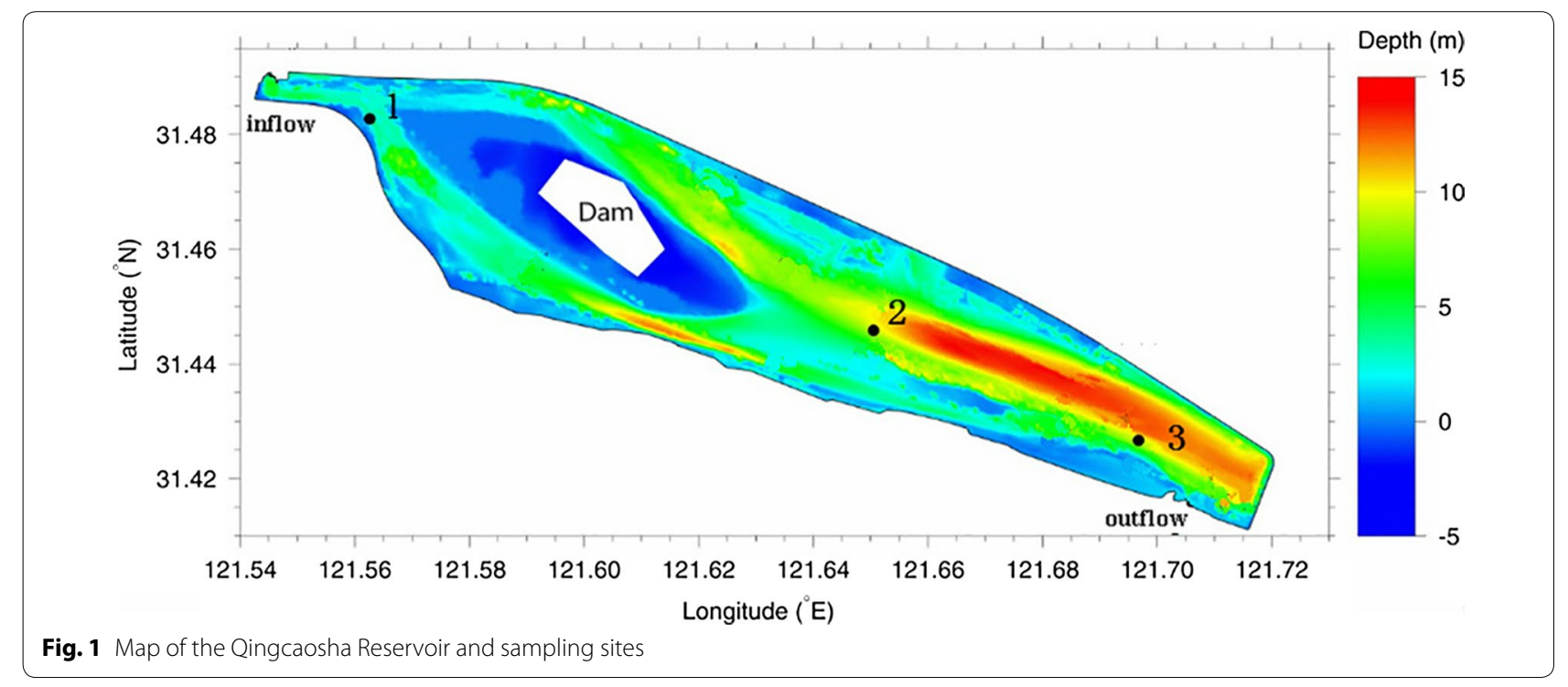


were collected monthly from April, 2016, to March, 2017. Water samples $(5 \mathrm{~L})$ were collected from the top $0.5 \mathrm{~m}$ of surface water, and sediment samples $(1 \mathrm{~kg})$ were collected from the top $5 \mathrm{~cm}$ of the riverbed using a core sampler. Each sample consists of a mixture of three different raw samples from one sampling site. All samples were stored in sterile bottles and then transported immediately to the laboratory, stored at $4{ }^{\circ} \mathrm{C}$ and pretreated within $24 \mathrm{~h}$.

\section{Sample pretreatment and DNA extraction}

Water samples $(500 \mathrm{~mL})$ were filtered through $0.22 \mu \mathrm{m}$ pore size polycarbonate membranes (GTTP, Millipore, Ireland), and then, the filter membranes were cut into small pieces and placed in extraction tubes provided in a Water DNA Kit (Omega, USA). Total DNA was extracted according to the instructions of the manufacturer. For sediments, $0.25 \mathrm{~g}$ dry samples were extracted using the PowerSoil DNA Isolation Kit (Mobio, USA) according to the manufacturer's protocol. The quality of extraction was verified by agarose gel electrophoresis, and the DNA quantities were measured using a UV-Vis spectrophotometer (Q5000, Quawell, USA).

\section{Quantification of ARG by qPCR}

Quantitative real-time PCR (qPCR) assays were carried out to quantitatively analyze the target genes from water and sediment samples, including the $16 \mathrm{~S}$ rRNA gene, two sulfonamide resistance genes (sul1, sul2), three tetracycline resistance genes $(\operatorname{tet} \mathrm{A}, \operatorname{tet} \mathrm{B}, \operatorname{tet} \mathrm{Q})$, three $\beta$-lactam resistance genes (OXA-1, TEM-1, ampC), two aminoglycoside resistance genes (str $\mathrm{A}$ and $s t r \mathrm{~B})$, two macrolide resistance genes (ermB, mphA), and the class 1 integron gene (int $\mathrm{I}-1)$. These target genes were relatively common in water environment, and related antibiotics have been detected in this reservoir [25]. Sequences of all primers of the target genes are listed in Additional file 1: Table S1 based on the published literature [17, 26-31]. All qPCR assays were performed in a $20 \mu \mathrm{L}$ total volume containing $0.5 \mu \mathrm{M}$ primer pairs (Sangon Biotech, China), $8 \mu \mathrm{L}$ of $\mathrm{dd}_{2} \mathrm{O}, 10 \mu \mathrm{L}$ of hot start reaction mix with $1 \times$ Sen$\operatorname{siMix}^{\mathrm{TM}} \mathrm{SYBR}^{\circledR}$ No-ROX Kit (Bioline, USA), and $1 \mu \mathrm{L}$ of template DNA. All reactions were conducted with a real-time PCR instrument (ABI 7500, Thermo Scientific, USA), and each run consisted of an initial preheating step at $95{ }^{\circ} \mathrm{C}$ for $5 \mathrm{~min}$, followed by 40 cycles with each cycle consisting of $15 \mathrm{~s}$ at $95^{\circ} \mathrm{C}$ and $30 \mathrm{~s}$ at different annealing temperatures as presented in Additional file 1: Table S1. Product specificity was validated by melting curve analysis $\left(60-98{ }^{\circ} \mathrm{C}, 0.5^{\circ} \mathrm{C}\right.$ per read, $6 \mathrm{~s}$ hold). For each sample, an additional diluted extract was simultaneously analyzed to avoid possible inhibitory effects in PCR processes. The specific amplified products were cloned in $\mathrm{pCR}^{\mathrm{TM}} 2.1 \mathrm{vec}-$ tor using a TA cloning Kit (Promega, USA).
Plasmids extracted from a known copy number of the positive colony were serially diluted to generate a standard curve. Reliable correlation coefficients $\left(R^{2}>0.99\right)$ and amplification efficiencies based on slopes between 90 and $110 \%$ for standard curves were obtained. The samples and positive plasmids along with sterile ultrapure water as a negative control were run in triplicate. The copy numbers of target genes were calculated based on the calibration curves. Gene concentrations in samples of water and sediments are presented as copies $/ \mathrm{mL}$ and copies/g (dry weight), respectively.

\section{Analysis of water quality parameters}

All reagents and solvents in the water quality analysis were analytical grade. Concentrations of chlorophyll- $a$ (Chl-a), chemical oxygen demand $\left(\mathrm{COD}_{\mathrm{Mn}}\right)$, ammonia nitrogen $\left(\mathrm{NO}_{4}{ }^{+}-\mathrm{N}\right)$, total nitrogen $(\mathrm{TN})$, and total phosphorus (TP) were measured according to Chinese national standards [11]. Dissolved organic carbon (DOC) was measured using a TOC analyzer (Shimazu, Japan), and $\mathrm{pH}$ was measured using a digital meter (pHS-25, Leici Instrument Co., Shanghai).

\section{Statistical analysis}

Correlation analysis was performed with Origin 9 (Originlab, USA). The redundancy analysis (RDA) used to analyze the effect of environmental factors on ARGs was performed using Canoco 5.0 (Biometris, Netherlands). A one-way ANOVA followed by Dunnett's test was used to assess the homogeneity of variance with a significance level of $5 \%(p=0.05)$. The calculations of heat map were performed using Microsoft Excel 2010.

\section{Results}

\section{Occurrence and abundance of a variety of ARGs in Qingcaosha Reservoir}

Figure 2 summarizes the abundance of all of the target genes in water and sediment samples from Qingcaosha Reservoir sampling sites over the entire year. The different colors of blocks represent absolute abundances of genes (log-transformed). Detailed information on abundance and detection frequency is presented in Additional file 1: Table S2. 16S rRNA genes and ARGs were detected in all samples, with detected concentrations higher in sediment than in water.

In particular, genes $16 \mathrm{~S}$ rRNA, int $\mathrm{I}-1$, sul 1 , sul 2 , tet $\mathrm{A}$, $s t r \mathrm{~A}$, and $s t r \mathrm{~B}$ were detected in $100 \%$ of the water and sediment samples. The concentration of $16 \mathrm{~S}$ rRNA genes was the highest, with copy numbers ranging from $1.4 \times 10^{5}$ to $1.1 \times 10^{8}$ copies $/ \mathrm{mL}$ in water and from $1.8 \times 10^{8}$ to $1.8 \times 10^{11}$ copies/g in sediment. For ARGs, sulfonamide resistance genes sul1, sul 2 were predominant in the Qingcaosha Reservoir, with the highest 


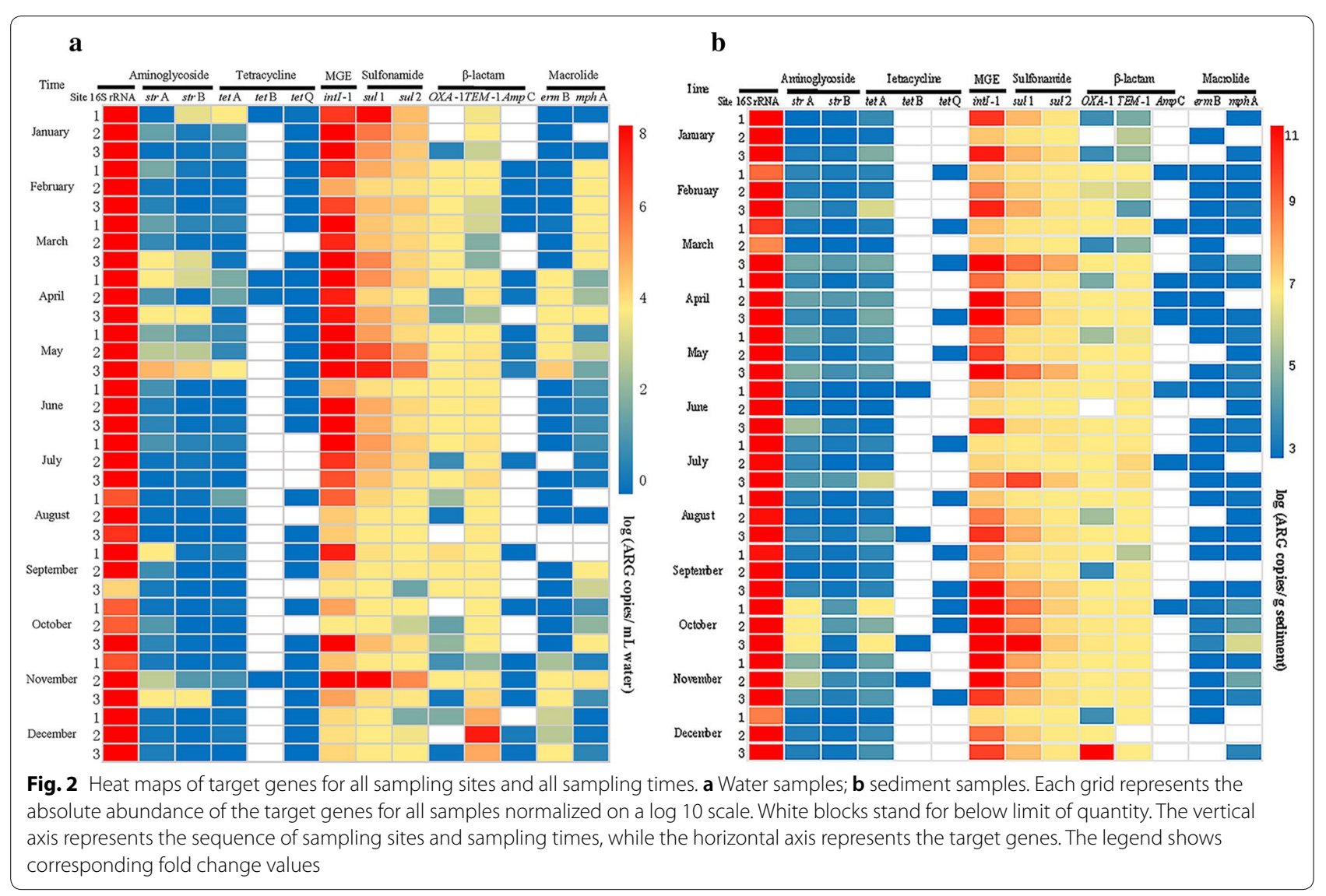

absolute abundance of $3.7 \times 10^{3}$ to $1.4 \times 10^{6}$ copies/ $\mathrm{mL}$ in water and $2.1 \times 10^{7}$ to $4.4 \times 10^{9}$ copies/g in sediment, respectively. Of the three tetracycline resistance genes, tet $\mathrm{A}$ was the most prevalent in this reservoir with an average concentration of $6.7 \times 10^{2}$ copies $/ \mathrm{mL}$ in water and $2.5 \times 10^{6} \mathrm{copies} / \mathrm{g}$ in sediment. However, the concentrations of tet $\mathrm{B}$ and tet $\mathrm{Q}$ were relatively low, especially the gene tet $\mathrm{B}$, detected in only $11.1 \%$ of the samples. Of the three $\beta$-lactam resistance genes, the overall trend in frequency in water and sediment samples was $T E M-1>O X A-1>a m p C$, with the lowest detection frequency being $a m p C$ in sediment. Two aminoglycoside resistance genes, str A and strB, were also found in the reservoir in high concentrations, with a peak value for strA of $1.1 \times 10^{7}$ copies/g in sediment. In addition, the concentrations of two macrolide resistance genes $\operatorname{ermB}$ (94.4\% in water and $77.8 \%$ in sediment) and mphA (91.7\% in water and $80.6 \%$ in sediment) were significantly lower than other resistance genes. Class 1 integron gene (int $\mathrm{I}-1$ ) was another highly abundant gene in this reservoir, with concentrations ranging from $9.5 \times 10^{3}$ to $4.0 \times 10^{6}$ copies $/ \mathrm{mL}$ in water and $1.8 \times 10^{8}$ to $1.3 \times 10^{10}$ copies/g in sediment.

\section{Temporal and spatial distribution of ARGs}

For analysis of temporal variation in a distinct way, we divided the data from 12 months into four seasons, including spring (March, April, and May), summer (June, July, and August), autumn (September, October, and November) and winter (December, January, and February). Figure 3 shows the seasonal variation of ARGs in water samples (Fig. 3a) and sediment samples (Fig. 3b). Copy numbers of TEM-1, strA, strB, and ermB higher in water samples in summer, and $O X A-1, T E M-1$ were higher in sediment in summer and autumn, respectively. However, the absolute abundance of ARGs exhibited no significant variation between seasons.

Figure 4 shows the spatial variation of ARGs in water samples (Fig. 4a) and sediment samples (Fig. 4b) from different sampling sites. In general, there were no significant differences between different sample sites although the absolute abundance of ARGs at site 3 was slightly higher than for other sediment sampling sites and tet $\mathrm{B}$ was not detected in water samples.

To minimize the variance in the abundance of ARGs possibly caused by divergences in background biomass and DNA extraction efficiency, the normalization of 

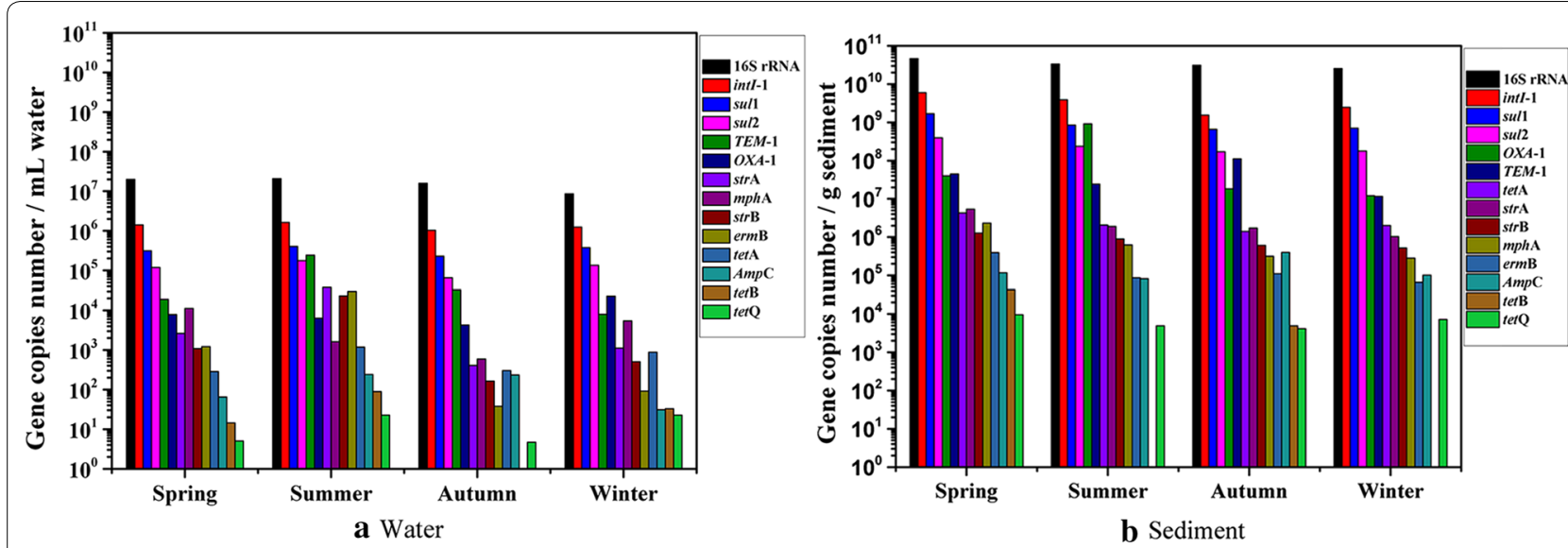

Fig. 3 Seasonal variation of ARGs in the samples from the Qingcaosha Reservoir. a Water samples; b sediment samples
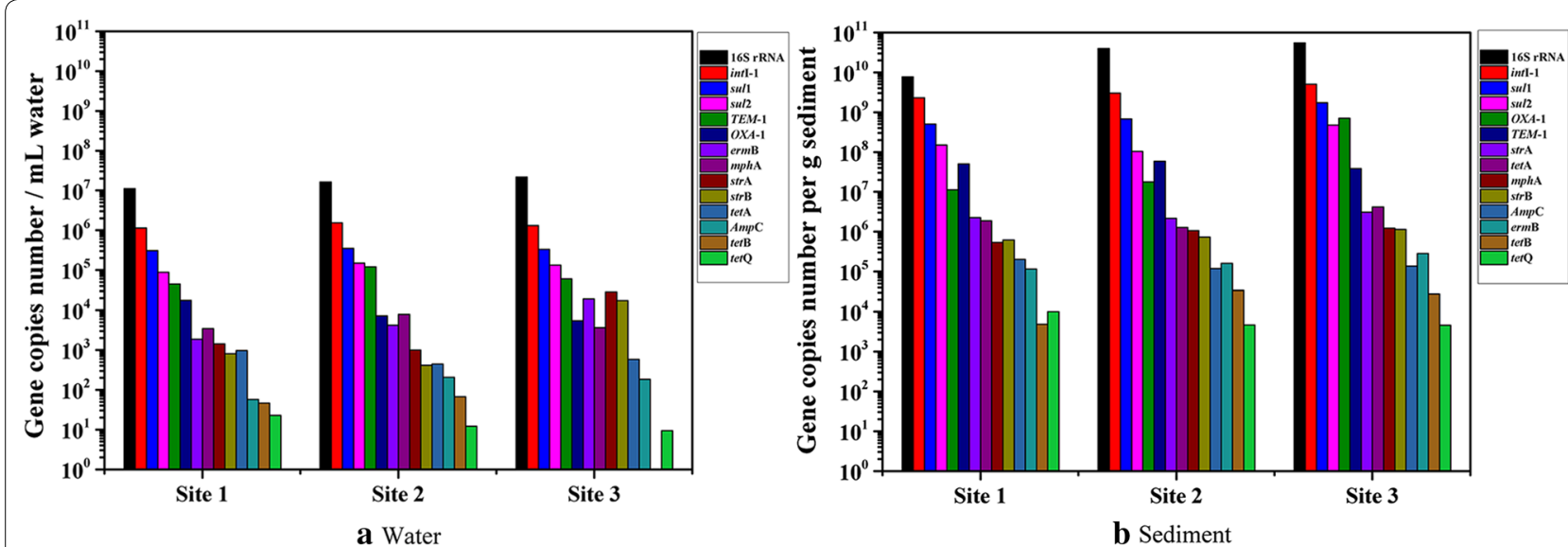

Fig. 4 Distribution of ARGs in the samples from different sampling sites in the Qingcaosha Reservoir. a Water samples; b sediment samples

absolute abundances was performed using the copy numbers of $16 \mathrm{~S}$ rRNA. A similar variation tendency in terms of seasonal and spatial distribution in both water and sediment was found in the relative abundances of ARGs (Additional file 1: Figs. S1, S2).

\section{Correlation analysis between abundances of ARGs}

A correlation analysis comparing the absolute and relative abundances of ARGs was performed, and the results of this analysis are summarized in Additional file 1: Tables S3, S4. intI-1, the gene with the highest relative abundance, had strong positive correlations with two sulfonamide resistance genes sul1, sul2 in both water and sediment $(p<0.01$, Fig. 5$)$. In sediment samples, a positive correlation was found between the relative abundances of int $\mathrm{I}-1$ and $s t r \mathrm{~A}, \operatorname{str} \mathrm{B}$, tet $\mathrm{A}(p<0.01$, Additional file 1: Table S4). Apart from that, we found significant correlations between most ARGs in the same class (Additional file 1: Tables S3, S4).

\section{Effects of water quality parameters on ARGs}

To analyze the key factors affecting the occurrence and abundance of ARGs, we recorded several water quality parameters including Chl- $a, \mathrm{COD}_{\mathrm{Mn}}, \mathrm{DOC}, \mathrm{pH}, \mathrm{TN}$, $\mathrm{TP}$, and $\mathrm{NH}_{4}{ }^{+}-\mathrm{N}$. The detailed results for water quality parameters are shown in Additional file 1: Table S5. The effective tool, RDA, was used to assess the potential response relationship between different ARGs and their associated water quality parameters (Fig. 6). intI-1, sul1, and $s u l 2$ were the predominant genes in the reservoir, and they had similar relationships with water quality parameters, mainly $\mathrm{COD}_{\mathrm{Mn}}$ and Chl- $a$, indicating that their formation was favored in circumstances with relatively higher $\mathrm{COD}_{\mathrm{Mn}}$ and Chl-a. For ARGs in water, most were negatively correlated with $\mathrm{TN}$ but positively correlated 

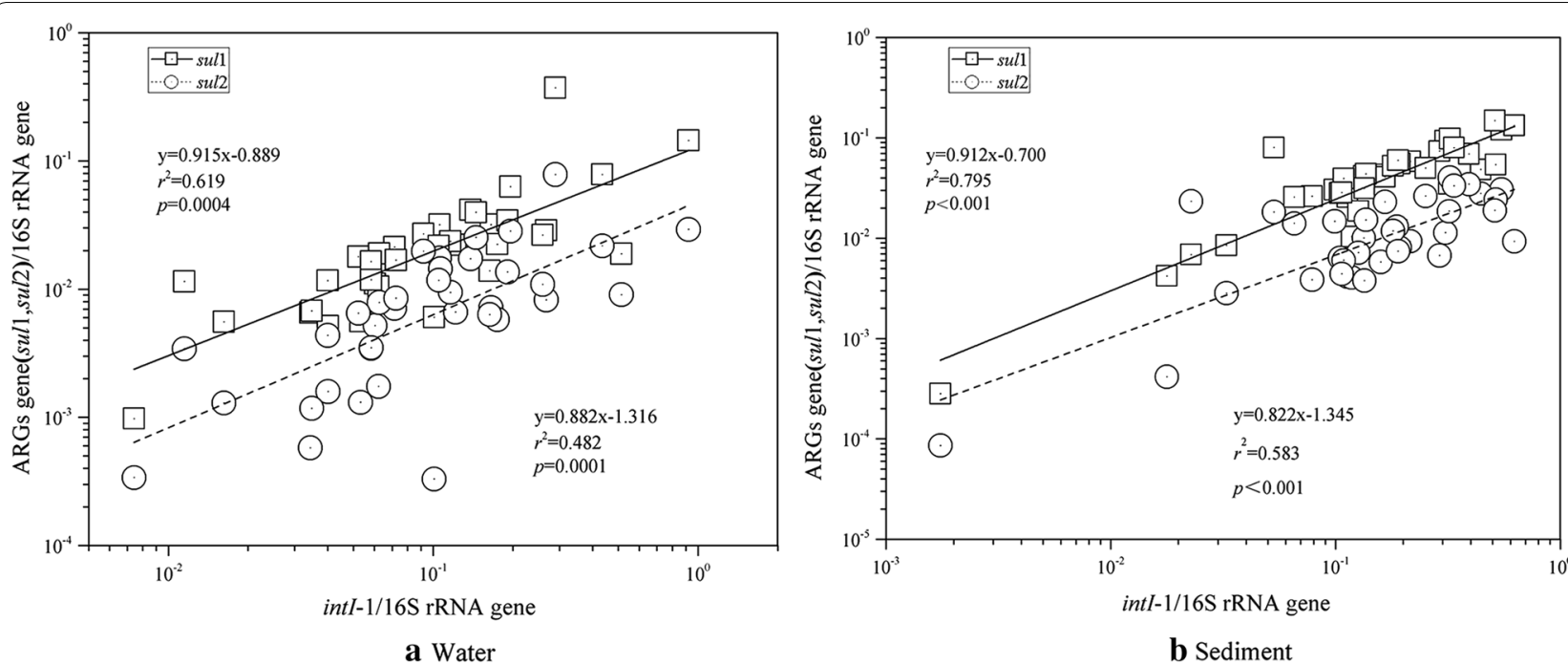

Fig. 5 Correlations between the relative abundance of class 1 integron and two sulfonamide resistance genes. a Correlations in water samples $(n=36)$; $\mathbf{b}$ correlations in sediment samples $(n=36)$

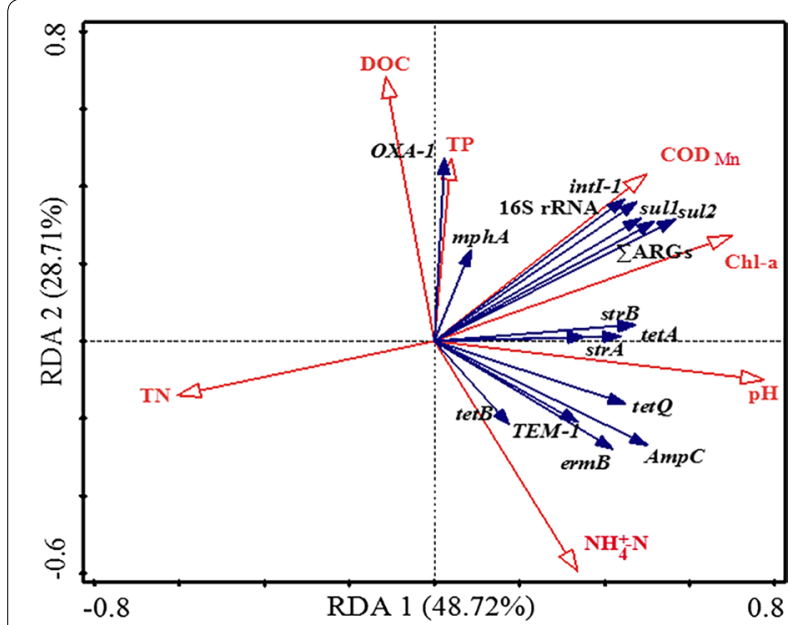

Fig. 6 Diagram of the RDA analysis between all ARGs and environmental factors in water

with $\mathrm{pH}$, which was further verified using a Pearson correlation coefficient (Additional file 1: Table S6).

\section{Discussion}

Among all detected genes, the copy numbers of sul1, sul2, and intI were predominant in this reservoir with high detection frequencies, which was consistent with previous reports for the Three Gorges Reservoir located in the upper reaches of the Yangtze River [32], but greater than those observed in studies of Tai Lake [8] and the Haihe River [18]. Sulfonamide resistance genes sul 1 and sul 2 encoded alternative drug-resistant variants of the dihydropteroate synthase enzymes and produced clinical resistance in Gram-negative enteric bacteria [33]. Multiple studies have shown that sulfonamide resistance genes are the most common ARGs in the environment $[8,18,32]$, which could possibly be linked to the widespread use of sulfonamides and resulting selective pressure for the corresponding ARGs [2]. For example, the release from aquaculture is one of the most important sources of antibiotics (including sulfonamide) in Yangtze Estuary [34]. According to previous studies of antibiotic residues in Qingcaosha Reservoir [25] and the Huangpu River [3], sulfamonomethoxine has a high abundance in this reservoir, ranging from not detected to $163.2 \mathrm{ng} / \mathrm{L}$, and in the Huangpu River, ranging from 2.05 to $623.27 \mathrm{ng} / \mathrm{L}$. Generally, the antibiotic contents in the environment were much lower (usually on the order of $10^{-9}-10^{-6}$ ) than the minimum inhibitory concentration acquired in the laboratory studies. It was estimated that the resistance of bacteria was gradually developed under the longterm selection pressure $[15,35]$. The previous study in the Haihe River also revealed a strong positive correlation $(p<0.01)$ between the relative abundance of $s u l 1$, sul2 and the concentration of sulfonamide [18]. Gene intI-1 is a mobile genetic element (MGE) that, as an indicator for the horizontal gene transfer potential of ARGs, has been frequently detected in the environment [36-38]. In our study, the relative abundance of int $\mathrm{I}-1$ was significantly positively correlated with some ARGs $(p<0.01)$, particularly sul 1 and sul2, indicating that intI-1 could facilitate the propagation of sul1 and sul2 in the Qingcaosha Reservoir. The gene sul1 is generally 
associated with class I integrons, and thus, a strong positive correlation is not surprising. Similar results were obtained in the Three Gorges Reservoir [32] and the Wenyu River [39].

Both aminoglycoside resistance genes (str $\mathrm{A}$ and $s t r \mathrm{~B}$ ) and macrolide resistance genes $(\operatorname{erm} \mathrm{B}$ and $m p h \mathrm{~A})$ had relatively high abundance/detection frequencies in the reservoir. Aminoglycosides are in frequent clinical use, and macrolides have been widely found in animal waste and agricultural soil [40]. Their corresponding ARGs have rarely been reported in aquatic environments. The $\beta$-lactam resistance gene TEM-1 was present in all water samples and $97.2 \%$ of the sediment samples, higher values than found in other studies on the Huangpu River $\left(10^{3}-10^{4}\right.$ copies $\left./ \mathrm{mL}\right)$ [41]. The concentration of $\beta$-lactam was reported in a previous study to be the highest among all antibiotics in Qingcaosha Reservoir [25]. The high concentration of $\beta$-lactam resistances genes could be caused by antibiotic long-term selection pressure.

The abundances of tetracycline resistance genes were relatively low in Qingcaosha Reservoir. Of the three tetracycline resistance genes, tetA was dominant while tet $\mathrm{B}$ possessed the lowest abundance and detection frequency. The differences among the three tetracycline resistance genes might be caused by different patterns of tetracycline antibiotic usage and different compositions of microflora [42]. Tetracycline resistance genes have been found to be among the most common ARGs in aquatic environments [43, 44]. The levels of tetracycline resistance genes were lower than those of Tai Lake [45], but they were in agreement with those detected in the Huangpu River [41]. Pearson correlation coefficients revealed positive correlations between ARGs of the same class such as tet $\mathrm{A}$, tet $\mathrm{B}$, and tet $\mathrm{Q}$, indicating that mobilizable plasmids containing ARGs can be transferred among microbial communities [46].

The temporal and spatial variations of ARGs may be the result of fluctuations in various factors including water temperature, flow conditions, surface run-off, and anthropogenic activities including antibiotics usage. Son et al. examined the abundance of 11 ARGs in rivers and reservoirs in South Korea and speculated that higher temperatures and nutrient conditions promoted the growth of microbes in summer, while general stress responses from adverse conditions such as low temperature and low nutrient promoted horizontal gene transfer of ARGs in winter [22]. The observation that the abundance of ARGs during wet seasons is lower than that in dry seasons could be due to dilution by rainfall [8]. However, in Qingcaosha Reservoir, no distinct temporal or spatial variations were observed except that the relative abundance of some ARGs was slightly higher in winter. We estimated that this was because of reduced influence from anthropogenic activities and relatively stable hydrological conditions. Similar distribution features were also found in studies of Taihu Lake [8].

In comparison with water, the concentrations of ARGs in sediments were significantly higher. Similar results have been found in previous studies [47-49]. On the one hand, a large number of microbes are present in sediments due to rich nutrients and the accumulation of particulate matter, which lead to a higher biomass in per $\mathrm{g}$ soil than in per $\mathrm{mL}$ water. For water samples, the process of pre-filtering would inevitably increase the loss in biomass [50]. On the other hand, clay components such as sediments can adsorb DNases that would otherwise hydrolyze free DNA, including ARGs, making it an ideal reservoir for ARGs $[18,19]$. The results of some studies have revealed strong positive correlations between the copy numbers of ARGs in water and sediments, suggesting the possible intermigration of ARGs between these two matrixes $[18,19]$; however, no such correlations were found in Qingcaosha Reservoir.

Consistent with previous studies of the influence of environmental factors on ARGs [51, 52], in this study, the total abundance of ARGs ( $\sum$ ARGs), 16S rRNA, intI1 , sul1, and sul 2 was positively correlated with Chl- $a$ and $\mathrm{COD}_{\mathrm{Mn}}$, indicating the potential impacts of these factors on the propagation of ARGs. The indicator Chl- $a$ represents the density of algal cells in the water, and $\mathrm{COD}_{\mathrm{Mn}}$ represents organic components that could be easily biodegraded and provide energy to ARBs (antibiotic resistant bacteria) for propagation; therefore, decreasing the numbers of algal cells would help to reduce the spread of ARGs [53]. Most ARGs in our study had negative correlations with $\mathrm{TN}$, inconsistent with some other studies $[48,54]$. We hypothesized that this was because nitrogen was demonstrated to be the main nutrient inhibiting the growth of algae in Qingcaosha Reservoir [24, 55]. Moreover, the aquatic $\mathrm{pH}$ affects the transfer efficiency of ARGs between cells [56]. Thus, it is crucial to pay attention to the impact of environmental factors on the propagation of ARGs when treating the ARG contaminants.

\section{Conclusions}

This one-year continuous monitoring of the occurrence and distribution of 12 ARGs and intI-1 found that ARGs were widely distributed in both water and sediment samples in Qingcaosha Reservoir, and no significant temporal or spatial variations were found. The concentrations of sulfonamide resistance genes sul1, sul2 were highest, while the tetracycline resistance gene tet $\mathrm{B}$ was the lowest. int $\mathrm{I}-1$ facilitated the proliferation and propagation of sul 1 and sul2, which may be the reason why sulfonamide resistance genes were so prevalent in the environment. Some environmental factors such as $\mathrm{pH}$, nitrogen, 
and phosphorus in the water were correlated with ARGs, indicating that they may play key roles for the formation or control of ARGs. In contrast to short-term studies, this study acquired detailed data regarding ARGs contaminants in the Qingcaosha water system over an entire year and could provide a scientific basis for reservoir management to deal with ARGs and related antibiotic pollution.

\section{Supplementary information}

Supplementary information accompanies this paper at (https://doi. org/10.1186/s12302-019-0265-2.

Additional file 1: Table S1. Primers used in quantitative PCR analysis. Table S2. Detection frequencies and absolute abundances of copy numbers for the target genes. Table S3. Correlation between relative abundance of ARGs in water. Table S4. Correlation between relative abundance of ARGs in sediment. Table S5. Water quality parameters of Qingcaosha Reservoir. Table S6. Correlation between ARGs and environmental factors in water. Figure $\mathbf{S} \mathbf{1}$. Seasonal variations in the relative abundance of ARGs in (a) water samples and (b) sediment samples from the Qingcaosha Reservoir. Figure S2. Relative abundance of ARGs in (a) water samples and (b) sediment samples from different sampling sites of the Qingcaosha Reservoir.

\section{Abbreviations}

ARGs: antibiotic resistance genes; ARBs: antibiotic resistant bacteria; qPCR: quantitative real-time PCR; Chl-a: chlorophyll-a; $\mathrm{COD}_{\mathrm{Mn}}$ : chemical oxygen demand; $\mathrm{NO}_{4}{ }^{+}-\mathrm{N}$ : ammonia nitrogen; TN: total nitrogen; TP: total phosphorus; $\Sigma$ ARGs: total abundance of ARGs.

\section{Acknowledgements}

Not applicable.

\section{Authors' contributions}

$\mathrm{ZH}, \mathrm{WZ}$, and $\mathrm{TX}$ were involved in the experiments and manuscript writing. $\mathrm{ZH}$, $W Z$, and TX were responsible for the data analysis. $Z H, T X$, and $B Z$ designed the study. TX and DY contributed to correction of the manuscript. All authors read and approved the final manuscript.

\section{Funding}

This study was funded by the National Natural Science Foundation of China (21876135, 21906121 and 21876136), the International Science and Technology Cooperation Program of China (2016YFE0123700), and the Foundation of Key Laboratory of Yangtze River Water Environment (Tongji University), Ministry of Education, China (YRWEF201803).

\section{Availability of data and materials}

The datasets obtained and analyzed in the current study are available from the corresponding author on reasonable request.

\section{Ethics approval and consent to participate}

Not applicable.

\section{Consent for publication}

Not applicable.

\section{Competing interests}

The authors declare that they have no competing interests.

\section{Author details}

${ }^{1}$ Key Laboratory of Yangtze River Water Environment, Ministry of Education, College of Environmental Science and Engineering, Tongji University, Shanghai 200092, China. ${ }^{2}$ Shanghai Institute of Pollution Control and Ecological Security, Shanghai 200092, China. ${ }^{3}$ National Engineering Laboratory for Lake Pollution Control and Ecological Restoration, Chinese Research Academy of Environmental Sciences, Beijing 100012, China.
Received: 7 August 2019 Accepted: 26 September 2019

Published online: 12 October 2019

\section{References}

1. Liu X, Lu S, Guo W, Xi B, Wang W (2018) Antibiotics in the aquatic environments: a review of lakes, China. Sci Total Environ 627:1195-1208

2. Zhang Q-Q, Ying G-G, Pan C-G, Liu Y-S, Zhao J-L (2015) comprehensive evaluation of antibiotics emission and fate in the river basins of China: source analysis, multimedia modeling, and linkage to bacterial resistance. Environ Sci Technol 49:6772-6782

3. Jiang L, Hu X, Yin D, Zhang H, Yu Z (2011) Occurrence, distribution and seasonal variation of antibiotics in the Huangpu River, Shanghai, China. Chemosphere 82:822-828

4. Stoll C, Sidhu JPS, Tiehm A, Toze S (2012) Prevalence of clinically relevant antibiotic resistance genes in surface water samples collected from Germany and Australia. Environ Sci Technol 46:9716-9726

5. Marti E, Variatza E, Luis Balcazar J (2014) The role of aquatic ecosystems as reservoirs of antibiotic resistance. Trends Microbiol 22:36-41

6. Ma L, Li A-D, Yin X-L, Zhang T (2017) The prevalence of integrons as the carrier of antibiotic resistance Genes in natural and man-made environments. Environ Sci Technol 51:5721-5728

7. Ahammad ZS, Sreekrishnan TR, Hands CL, Knapp CW, Graham DW (2014) Increased Waterborne bla(NDM-1) Resistance Gene Abundances Associated with Seasonal Human Pilgrimages to the Upper Ganges River. Environ Sci Technol 48:3014-3020

8. Stange C, Yin D, Xu T, Guo X, Schaefer C, Tiehm A (2019) Distribution of clinically relevant antibiotic resistance genes in Lake Tai, China. Sci Total Environ 655:337-346

9. Bengtsson-Palme J, Larsson DGJ (2015) Antibiotic resistance genes in the environment: prioritizing risks. Nat Rev Microbiol 13:396

10. Zhang Y, Niu Z, Zhang Y, Zhang K (2018) Occurrence of intracellular and extracellular antibiotic resistance genes in coastal areas of Bohai Bay (China) and the factors affecting them. Environ Pollut 236:126-136

11. Li S, Zhang R, Hu J, Shi W, Kuang Y, Guo X, Sun W (2019) Occurrence and removal of antibiotics and antibiotic resistance genes in natural and constructed riverine wetlands in Beijing, China. Sci Total Environ 664:546-553

12. Duan M, Gu J, Wang X, Li Y, Zhang R, Hu T, Zhou B (2019) Factors that affect the occurrence and distribution of antibiotic resistance genes in soils from livestock and poultry farms. Ecotoxicol Environ Saf 180:114-122

13. Chen J, Su Z, Dai T, Huang B, Mu Q, Zhang Y, Wen D (2019) Occurrence and distribution of antibiotic resistance genes in the sediments of the East China Sea bays. J Environ Sci China 81:156-167

14. Li J, Cao J, Zhu Y-g, Chen Q-I, Shen F, Wu Y, Xu S, Fan H, Da G, Huang R-j, Wang J, de Jesus AL, Morawska L, Chan CK, Peccia J, Yao M (2018) Global survey of antibiotic resistance genes in air. Environ Sci Technol 52:10975-10984

15. Zhang Q-Q, Tian G-M, Jin R-C (2018) The occurrence, maintenance, and proliferation of antibiotic resistance genes (ARGs) in the environment: influencing factors, mechanisms, and elimination strategies. Appl Microbiol Biotechnol 102:8261-8274

16. Zhai W, Yang F, Mao D, Luo Y (2016) Fate and removal of various antibiotic resistance genes in typical pharmaceutical wastewater treatment systems. Environ Sci Pollut Res 23:12030-12038

17. Dang B, Mao D, Xu Y, Luo Y (2017) Conjugative multi-resistant plasmids in Haihe River and their impacts on the abundance and spatial distribution of antibiotic resistance genes. Water Res 111:81-91

18. Luo Y, Mao D, Rysz M, Zhou Q, Zhang H, Xu L, Alvarez PJJ (2010) Trends in antibiotic resistance genes occurrence in the Haihe River, China. Environ Sci Technol 44:7220-7225

19. Engemann CA, Keen PL, Knapp CW, Hall KJ, Graham DW (2008) Fate of tetracycline resistance genes in aquatic systems: migration from the water column to peripheral biofilms. Environ Sci Technol 42:5131-5136

20. Su H-C, Liu Y-S, Pan C-G, Chen J, He L-Y, Ying G-G (2018) Persistence of antibiotic resistance genes and bacterial community changes in drinking water treatment system: from drinking water source to tap water. Sci Total Environ 616:453-461

21. Hao H, Shi D-y, Yang D, Yang Z-w, Qiu Z-g, Liu W-I, Shen Z-q, Yin J, Wang H-r, Li J-w, Wang H, Jin M (2019) Profiling of intracellular and extracellular antibiotic resistance genes in tap water. J Hazard Mater 365:340-345 
22. Son D-i, Aleta P, Park M, Yoon H, Cho KH, Kim YM, Kim S (2018) Seasonal Changes in Antibiotic Resistance Genes in Rivers and Reservoirs in South Korea. J Environ Qual 47:1079-1085

23. Lu L, Liu J, Li Z, Liu Z, Guo J, Xiao Y, Yang J (2018) Occurrence and Distribution of tetracycline antibiotics and resistance genes in Longshore sediments of the three gorges reservoir, China. Front Microbiol 9:1911

24. Ou H-S, Wei C-H, Deng Y, Gao N-Y (2013) Principal component analysis to assess the composition and fate of impurities in a large riverembedded reservoir: qingcaosha Reservoir. Environ Sci Process Impacts $15: 1613-1621$

25. Jiang Y, Xu C, Wu X, Chen Y, Han W, Gin KY-H, He Y (2018) Occurrence, seasonal variation and risk assessment of antibiotics in Qingcaosha reservoir. Water 10:115

26. Suzuki MT, Taylor LT, DeLong EF (2000) Quantitative analysis of smallsubunit rRNA genes in mixed microbial populations via 5'-nuclease assays. Appl Environ Microbiol 66:4605-4614

27. Pei R, Kim S-C, Carlson KH, Pruden A (2006) Effect of River Landscape on the sediment concentrations of antibiotics and corresponding antibiotic resistance genes (ARG). Water Res 40:2427-2435

28. Ng LK, Martin I, Alfa M, Mulvey M (2001) Multiplex PCR for the detection of tetracycline resistant genes. Mol Cell Probes 15:209-215

29. Yang Y, Zhang T, Zhang X-X, Liang D-W, Zhang M, Gao D-W, Zhu H-G, Huang Q-G, Fang HHP (2012) Quantification and characterization of $\beta$-lactam resistance genes in 15 sewage treatment plants from East Asia and North America. Appl Microbiol Biotechnol 95:1351-1358

30. Mao D, Yu S, Rysz M, Luo Y, Yang F, Li F, Hou J, Mu Q, Alvarez PJJ (2015) Prevalence and proliferation of antibiotic resistance genes in two municipal wastewater treatment plants. Water Res 85:458-466

31. Lu Z, Na G, Gao H, Wang L, Bao C, Yao Z (2015) Fate of sulfonamide resistance genes in estuary environment and effect of anthropogenic activities. Sci Total Environ 527:429-438

32. Yan M, Xu C, Huang Y, Nie H, Wang J (2018) Tetracyclines, sulfonamides and quinolones and their corresponding resistance genes in the Three Gorges Reservoir, China. Sci Total Environ 631-632:840-848

33. Skold O (2000) Sulfonamide resistance: mechanisms and trends. Drug Resist Updates 3:155-160

34. Guo X, Feng C, Gu E, Tian C, Shen Z (2019) Spatial distribution, source apportionment and risk assessment of antibiotics in the surface water and sediments of the Yangtze Estuary. Sci Total Environ 671:548-557

35. Qiao M, Ying G-G, Singer AC, Zhu Y-G (2018) Review of antibiotic resistance in China and its environment. Environ Int 110:160-172

36. Du J, Ren H, Geng J, Zhang Y, Xu K, Ding L (2014) Occurrence and abundance of tetracycline, sulfonamide resistance genes, and class 1 integron in five wastewater treatment plants. Environ Sci Pollut Res 21:7276-7284

37. Sandberg KD, LaPara TM (2016) The fate of antibiotic resistance genes and class 1 integrons following the application of swine and dairy manure to soils. Fems Microbiol Ecol 92:fiw001

38. Muziasari WI, Parnanen K, Johnson TA, Lyra C, Karkman A, Stedtfeld RD, Tamminen M, Tiedje JM, Virta M (2016) Aquaculture changes the profile of antibiotic resistance and mobile genetic element associated genes in Baltic Sea sediments. Fems Microbiol Ecol 92:fiw052

39. Xu Y, Guo C, Luo Y, Lv J, Zhang Y, Lin H, Wang L, Xu J (2016) Occurrence and distribution of antibiotics, antibiotic resistance genes in the urban rivers in Beijing, China. Environ Pollut 213:833-840

40. Luby EM, Moorman TB, Soupir ML (2016) Fate and transport of tylosin-resistant bacteria and macrolide resistance genes in artificially drained agricultural fields receiving swine manure. Sci Total Environ 550:1126-1133
41. Jiang L, Hu X, Xu T, Zhang H, Sheng D, Yin D (2013) Prevalence of antibiotic resistance genes and their relationship with antibiotics in the Huangpu River and the drinking water sources, Shanghai, China. Sci Total Environ 458:267-272

42. Gao P, Mao D, Luo Y, Wang L, Xu B, Xu L (2012) Occurrence of sulfonamide and tetracycline-resistant bacteria and resistance genes in aquaculture environment. Water Res 46:2355-2364

43. Roberts MC (2005) Update on acquired tetracycline resistance genes. FEMS Microbiol Lett 245:195-203

44. Keen PL, Knapp CW, Hall KJ, Graham DW (2018) Seasonal dynamics of tetracycline resistance gene transport in the Sumas River agricultural watershed of British Columbia, Canada. Sci Total Environ 628-629:490-498

45. Zhang $X$, Wu B, Zhang Y, Zhang T, Yang L, Fang HHP, Ford T, Cheng S (2009) Class 1 integronase gene and tetracycline resistance genes tetA and tetC in different water environments of Jiangsu Province, China. Ecotoxicology 18:652-660

46. Chopra I, Roberts M (2001) Tetracycline antibiotics: Mode of action, applications, molecular biology, and epidemiology of bacterial resistance. Microbiol Mol Biol Rev 65:232

47. Niu Z-G, Zhang K, Zhang Y (2016) Occurrence and distribution of antibiotic resistance genes in the coastal area of the Bohai Bay, China. Mar Pollut Bull 107:245-250

48. Zhang K, Niu Z-G, Lv Z, Zhang Y (2017) Occurrence and distribution of antibiotic resistance genes in water supply reservoirs in Jingjinji area, China. Ecotoxicology 26:1284-1292

49. Dong P, Cui Q, Fang T, Huang Y, Wang H (2019) Occurrence of antibiotic resistance genes and bacterial pathogens in water and sediment in urban recreational water. J Environ Sci China 77:65-74

50. Mao D, Luo Y, Mathieu J, Wang Q, Feng L, Mu Q, Feng C, Alvarez PJJ (2014) Persistence of extracellular DNA in river sediment facilitates antibiotic resistance gene propagation. Environ Sci Technol 48:71-78

51. Jia J, Guan Y, Cheng M, Chen H, He J, Wang S, Wang Z (2018) Occurrence and distribution of antibiotics and antibiotic resistance genes in Ba River, China. Sci Total Environ 642:1136-1144

52. Shi W, Zhang H, Li J, Liu Y, Shi R, Du H, Chen J (2019) Occurrence and spatial variation of antibiotic resistance genes (ARGs) in the Hetao Irrigation District, China. Environ Poll 251:792-801

53. Lu Z, Song L, Zhao Z, Ma Y, Wang J, Yang H, Ma H, Cai M, Codling G, Ebinghaus R, Xie Z, Giesy JP (2015) Occurrence and trends in concentrations of perfluoroalkyl substances (PFASs) in surface waters of eastern China. Chemosphere 119:820-827

54. MCKinney CW, Loftin KA, Meyer MT, Davis JG, Pruden A (2010) tet and sul antibiotic resistance genes in livestock lagoons of various operation type, configuration, and antibiotic occurrence. Environ Sci Technol 44:6102-6109

55. Huang X, Huang Z, Chen X-P, Zhang D, Zhou J, Wang X, Gao N (2018) The predominant phytoplankton of Pseudoanabaena holding specific biosynthesis gene-derived occurrence of 2-MIB in a drinking water reservoir. Environ Sci Pollut Res 25:19134-19142

56. Qiu Z, Yu Y, Chen Z, Jin M, Yang D, Zhao Z, Wang J, Shen Z, Wang X, Qian D, Huang A, Zhang B, Li J-W (2012) Nanoalumina promotes the horizontal transfer of multiresistance genes mediated by plasmids across genera. Proc Natl Acad Sci USA 109:4944-4949

\section{Publisher's Note}

Springer Nature remains neutral with regard to jurisdictional claims in published maps and institutional affiliations. 